ARTICLE

https://doi.org/10.1038/s41467-019-09336-1

\title{
Syngas to light olefins conversion with high olefin/paraffin ratio using $\mathrm{ZnCrO}_{x} / \mathrm{AlPO}-18$ bifunctional catalysts
}

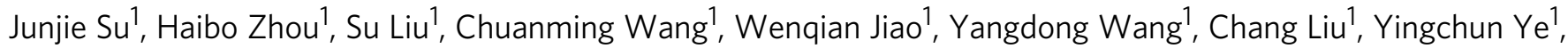
Lin Zhang ${ }^{1}$, Yu Zhao ${ }^{1}$, Hongxing Liu', Dong Wang ${ }^{1}$, Weimin Yang ${ }^{1}$, Zaiku Xie ${ }^{2} \&$ Mingyuan $\mathrm{He}^{3}$

Direct synthesis of light olefins from syngas (STO) using a bifunctional catalyst composed of oxide and zeolite has attracted extensive attention in both academia and industry. It is highly desirable to develop robust catalysts that could enhance the $\mathrm{CO}$ conversion while simultaneously maintain high selectivity to $\mathrm{C} 2-\mathrm{C} 4$ olefins. Herein, we report a bifunctional catalyst consisting of $\mathrm{ZnCr}$ binary oxide $\left(\mathrm{ZnCrO}_{\mathrm{x}}\right)$ and low-Si AIPO-18 zeolite, showing both satisfying selectivity to $\mathrm{C} 2-\mathrm{C} 4$ olefins of $45.0 \%\left(86.7 \%, \mathrm{CO}_{2}\right.$ free) and high olefin/ paraffin ratio of 29.9 at the $\mathrm{CO}$ conversion of $25.2 \%$ under mild reaction conditions ( $4.0 \mathrm{MPa}$, $390^{\circ} \mathrm{C}$ ). By optimizing the reaction conditions, the CO conversion could be markedly increased to $49.3 \%$ with a slight drop in selectivity. $\mathrm{CD}_{3} \mathrm{CN} / \mathrm{CO}-\mathrm{FTIR}$ characterizations and theoretical calculations demonstrate that low-Si AIPO-18 zeolite has lower acid strength, and is therefore less reactive toward the hydride transfer in the STO reaction, leading to a higher olefin/paraffin ratio.

\footnotetext{
${ }^{1}$ State Key Laboratory of Green Chemical Engineering and Industrial Catalysis, Shanghai Research Institute of Petrochemical Technology, SINOPEC Corp. Shanghai 201208, China. ${ }^{2}$ China Petrochemical Corporation (SINOPEC Group), Beijing 100728, China. ${ }^{3}$ Shanghai Key Laboratory of Green Chemistry and Chemical Processes, School of Chemistry and Molecular Engineering, East China Normal University, Shanghai 200062, China. These authors contributed equally: Junjie Su, Haibo Zhou. Correspondence and requests for materials should be addressed to Y.W. (email: wangyd.sshy@sinopec.com) or to Z.X. (email: xzk@sinopec.com) or to M.H. (email: hemingyuan@126.com)
} 
ight olefins $(\mathrm{C} 2-\mathrm{C} 4)$ are very important chemical materials in the whole industrial manufacture chain with huge market demand. In the past decade, methanol to olefins (MTO) conversion, a new technology for producing light olefins, has been successfully industrialized ${ }^{1-4}$. However, to produce olefins from raw materials such as coal or natural gas, many precedent processes including syngas production and methanol synthesis are required before the MTO process, highly increasing investment cost and energy consumption. The direct conversion of syngas into light olefins (STO) is therefore strongly desired since $1980 \mathrm{~s}^{1,5,6}$

Great efforts have been devoted to the direct STO conversion using modified Fischer-Tropsch (FT) catalysts ${ }^{7-13}$. But it is generally difficult to achieve high selectivity to $\mathrm{C} 2-\mathrm{C} 4$ hydrocarbons, owing to the limitation of the Anderson-Schulz-Flory (ASF) distribution. Although some modified methods like introducing a second zeolite phase to conventional FT catalysts can optimize the hydrocarbons distribution, the olefin selectivity is still limited ${ }^{14-18}$. More recently, using a bifunctional catalyst containing $\mathrm{ZnCr}$ oxide and SAPO-34 zeolite, Bao and coworkers ${ }^{19}$ first reported direct synthesis of light olefins from syngas exhibiting an excellent selectivity of $80 \%\left(\mathrm{CO}_{2}\right.$ free) for light olefins at $\sim 17 \% \mathrm{CO}$ conversion. Inspired by this pioneered work, several kinds of bifunctional catalysts to directly convert $\mathrm{CO}$ or $\mathrm{CO}_{2}$ into light olefins were then developed, including $\mathrm{ZnZr} / \mathrm{SAPO}-34^{20}$, $\mathrm{ZnAl} / \mathrm{SAPO}-34^{21}, \mathrm{MnO}_{\mathrm{x}} / \mathrm{SAPO}-34^{22}$, and InZr/SAPO- $34^{23}$. Interestingly, as the selectivity of light olefins is close to that of the MTO reaction, this STO process therefore holds the potential to be a promising alternative to directly produce light olefins from syngas.

Despite the great progress made previously, the industrialization of the direct conversion is still impeded by several major challenges. First, the $\mathrm{CO}$ conversion should be significantly improved to decrease the energy consumption for the separation of unconverted syngas from light olefins products. Second, the effective utilization of carbon resources is low as the result of undesired $\mathrm{CO}_{2}$ production; currently, either modified FT catalysts ${ }^{7,24}$ or bifunctional catalysts ${ }^{19-23}$, both show a $\mathrm{CO}_{2}$ selectivity of higher than $45 \%$. However, for the conversion of hydrogen lean syngas derived from coal or biomass, it's necessary to modulate $\mathrm{H}_{2} / \mathrm{CO}$ ratio via water-gas shift reaction. Consequently, high $\mathrm{CO}_{2}$ selectivity can enable the in situ re-adjustment of the $\mathrm{H}_{2} / \mathrm{CO}$ molar ratio, which is benefit for coal- or biomass-based syngas conversion. Third, among the $\mathrm{CO}_{2}$-free products, it is very necessary to enhance the selectivity to the desired products of light olefins while reduce the selectivity to paraffins and maintain high $\mathrm{CO}$ conversion. The maximal CO conversion of the direct STO process using bifunctional catalysts is reported to be only $\sim 17 \%{ }^{19}$. As olefins may be further hydrogenated into paraffins in the presence of hydrogen ${ }^{23}$, the selectivity of $\mathrm{C} 2-\mathrm{C} 4$ paraffins would be increased when enhancing the $\mathrm{CO}$ conversion. So it is very challenging to simultaneously achieve high CO conversion and selectivity to light olefins in the direct STO conversion.

We previously found that the olefin/paraffin ratio could be increased by modifying the oxide component with alkali metals to reduce the hydrogenation activity ${ }^{23}$. However, this approach also leads to the decrease of $\mathrm{CO}$ conversion. In addition, it was demonstrated that the acidity and/or structures of zeolites can affect the distribution of products. For example, when ZSM-5 with stronger acidity is used as the zeolite component, the primary products of syngas conversion are paraffins ${ }^{18}$ or aromatics ${ }^{25,26}$, in sharp contrast to the product distribution of SAPO-34 zeolites in which high-light olefins selectivity of $~ 80 \%$ $\left(\mathrm{CO}_{2}\right.$ free $)$ and olefin/paraffin ratio of $\sim 5$ was achieved. Wang et al. ${ }^{20}$ reported that the olefins selectivity can be slightly enhanced by reducing $\mathrm{Si}$ contents in SAPO-34; the maximum olefin/paraffin ratio is $<6$ at the CO conversion is $11 \%$. These findings imply that tailoring the structure and acidity of zeolites in bifunctional catalysts could be very effective to improve the $\mathrm{CO}$ conversion and the olefin selectivity. However, the relationship between structural properties (acidity and cage structure) of zeolites and product distribution in syngas conversion is still unclear, which is closely related to whether the reaction performance, and even whether the industrial competitiveness of this system, can be further improved.

So far, SAPO-34 is usually selected as the candidate of zeolites for $\mathrm{C}-\mathrm{C}$ coupling to produce light olefins due to its eightmembered ring channels with the size of $3.8 \AA \times 3.8 \AA$ which is beneficial to the diffusion of light olefins. In this way, no significant enhancement on catalytic performance was observed by altering the oxide component in bifunctional catalysts ${ }^{19-23}$. Different from previous strategy, in this work we design a bifunctional catalyst composed of the $\mathrm{ZnCrO}_{\mathrm{x}}$ and a zeolite with AEI framework, whose main channel is also eight-membered ring channels with the size of $3.8 \AA \times 3.8 \AA$. The bifunctional catalyst containing $\mathrm{ZnCrO}_{\mathrm{x}}$ and low-Si AlPO-18 zeolite shows an excellent performance, achieving a $\mathrm{C} 2-\mathrm{C} 4$ olefin selectivity of $87 \%\left(\mathrm{CO}_{2}\right.$ free $)$ and olefin/paraffin ratio of 29.9 at the $\mathrm{CO}$ conversion of $25.2 \%$.

\section{Results}

Characterization of the catalyst materials. The geometry structures of zeolite components were characterized to shed light on the influence of zeolite structure and acidity on syngas conversion. The XRD patterns in Fig. 1a show that AlPO-18 and SAPO-34 zeolites are typical AEI and CHA topology structure with high crystallinity, respectively. The SAPO-34 zeolite appears as cuboids with crystal size of 2-4 $\mu \mathrm{m}$ (Fig. 1d), which is a typical crystal morphology of the CHA framework (trigonal). The AlPO18 crystals show nanosheet morphologies with the diameter of 1-4 $\mu \mathrm{m}$ and the thickness of $100 \mathrm{~nm}$ (Fig. 1b), typical features of the AEI framework (orthorhombic). Their chemical compositions, BET surface areas and pore volumes of the calcined samples are provided in Table 1. The surface area of calcined AlPO-18 is $592 \mathrm{~m}^{2} \mathrm{~g}^{-1}$, higher than that of SAPO-34 $\left(493 \mathrm{~m}^{2} \mathrm{~g}^{-1}\right)$. There is no obvious difference in the micropore volume, but the total pore volume of AlPO-18 is twice larger than SAPO-34, owing to the increase of mesoporous pores caused by reduced crystal sizes.

Atomic hyperfine structures of two zeolites were also determined using the spherical aberration-corrected STEM, as shown in Fig. 1c, e. We found that AlPO-18 shows eightmembered framework rings originated from the (001) crystal plane, while SAPO-34 mainly exposes the (001) crystal plane with six-membered rings. It was difficult to detect other planes of SAPO-34 with eight-membered rings, such as the (100), (010), and (110), even by adjusting the measurement direction of STEM, indicating that the number of exposed eight-membered ring channels in AlPO-18 is higher than the SAPO-34 zeolite.

Catalytic performances. We thoroughly investigated and compared the catalytic performance and product distribution of different catalysts (Fig. 2). The significance of zeolite component is demonstrated. Single component of $\mathrm{ZnCrO}_{\mathrm{x}}$ exhibits very low CO conversion of $4.8 \%$ and also low selectivity to olefins $(19.0 \%)$ at $4.0 \mathrm{MPa}, 390^{\circ} \mathrm{C}$. By integrating with zeolites (mass ratio 1:1; granule-stacking), bifunctional catalysts generally show much higher CO conversion $(>15 \%)$ and light olefins selectivity $(>40 \%)$ under the same reaction conditions. However, significant differences also exist among those bifunctional catalysts. The $\mathrm{ZnCr} /$ AlPO-18 bifunctional catalyst shows a CO conversion of $16.6 \%$ with a $\mathrm{C} 2-\mathrm{C} 4$ olefin selectivity of $42.7 \%\left(80.6 \%, \mathrm{CO}_{2}\right.$ free). In addition, a olefin/paraffin ratio of 27.7 is obtained, which is 
higher than the value of 6.8 for the $\mathrm{ZnCr} / \mathrm{SAPO}-34$ catalyst. The lower CO conversion and oxygenate selectivity imply that the driving force of AlPO-18 zeolite is insufficient for this reaction, possibly relevant with two aspects of the particle size and acidity. Regarding the former aspect, we further synthesized an AlPO-18 zeolite with 1-2 $\mu \mathrm{m}$ particle size (AlPO-18-L, Supplementary Fig. 1) to investigate the size effect of zeolite on the catalytic performance (Supplementary Table 1). The ZnCr/AlPO-18-L shows even lower CO conversion (8.8\%) and a higher selectivity to oxygenates (DME and $\mathrm{MeOH}, 30.8 \%$ ). However, it is noteworthy that although the total selectivity of hydrocarbons decreases, the $\mathrm{C} 2-\mathrm{C} 4$ olefin/paraffin ratio remains at a level of
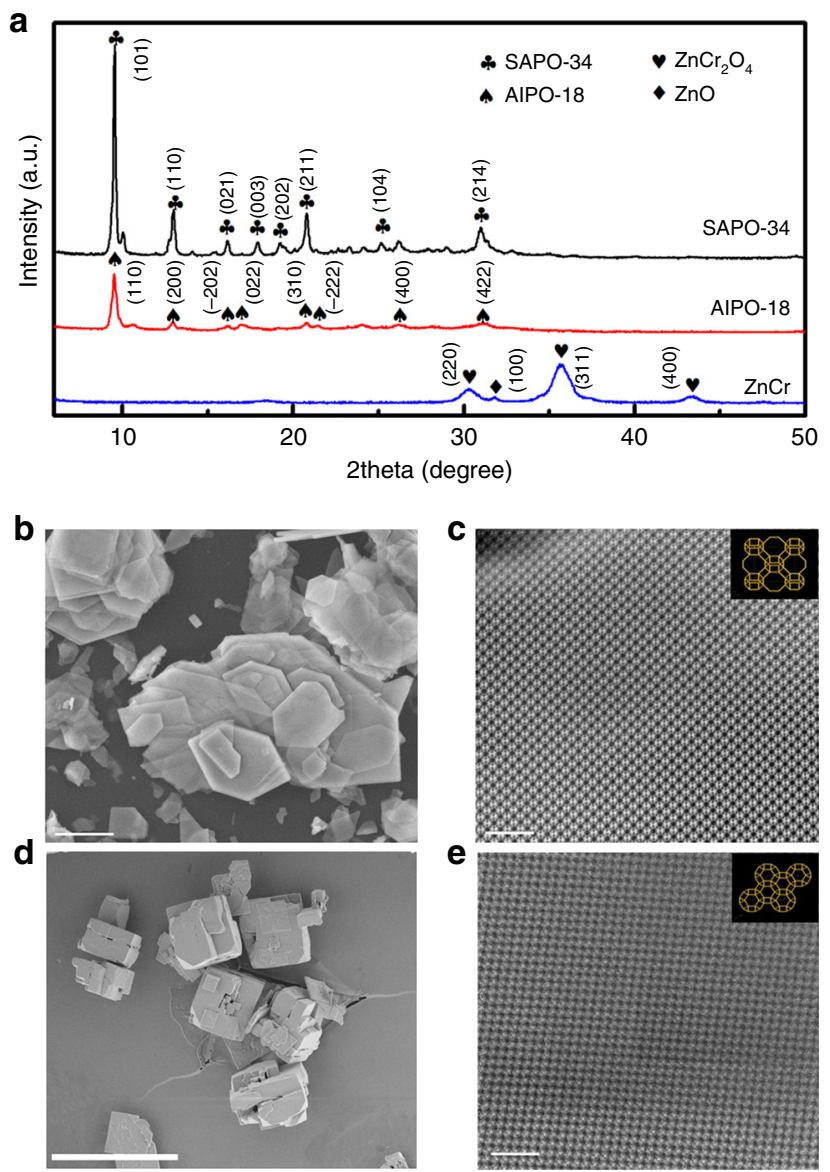

Fig. 1 Microstructure of bifunctional catalysts. a XRD patterns of the calcined $\mathrm{ZnCrO}_{x}$, AIPO-18 and SAPO-34 zeolites, SAPO-34(club), AIPO-18 (spade), $\mathrm{ZnCr}_{2} \mathrm{O}_{4}$ (heart), and $\mathrm{ZnO}$ (diamond). b SEM images of the calcined AIPO-18 (scale bar, $1 \mu \mathrm{m}$ ). c Aberration-corrected STEM images and the corresponding framework images of the calcined AIPO-18 (scale bar, $5 \mathrm{~nm}$ ). d SEM images of the calcined SAPO-34 (scale bar, $10 \mu \mathrm{m})$. e Aberration-corrected STEM images and the corresponding framework images of the calcined SAPO-34 (scale bar, $5 \mathrm{~nm}$ )
27.5, which means that the particle sizes of zeolite does not show significant effect on hydrocarbon distribution. In the case of the acidity effect, we synthesized a low-Si AlPO-18 zeolite ( $\mathrm{Si} / \mathrm{Al}$ ratio $=0.013$ ) by using boehmite containing trace $\mathrm{Si}$ impurities as $\mathrm{Al}$ resource. The $\mathrm{ZnCr} / \mathrm{low}-\mathrm{Si} \mathrm{AlPO}-18$ bifunctional catalyst shows CO conversion of $25.2 \%$, which is close to that of $\mathrm{ZnCr} /$ SAPO-34 catalyst. Meanwhile, the selectivity of C2-C4 olefins is increased to $45.0 \%\left(86.7 \% \mathrm{CO}_{2}\right.$ free $)$, while that of $\mathrm{C} 2-\mathrm{C} 4$ paraffins is as low as $1.5 \%$, leading to a C2-C4 olefin/paraffin ratio of 29.9. In addition, it is necessary to note that our results of $\mathrm{ZnCr} /$ low-Si AlPO-18 are also markedly better than previously reported catalysts, such as $\mathrm{ZnCr} / \mathrm{SAPO}-34^{19}, \mathrm{ZnZr} / \mathrm{SAPO}-34^{20}$, $\mathrm{MnO}_{\mathrm{x}} / \mathrm{SAPO}-34^{22}$, and InZr/SAPO- $34^{23}$, in the case of olefin/ paraffin ratio.

The influence of reaction conditions, such as the GHSV and reaction pressure, on catalytic performance was then studied. As shown Fig. 3a, the $\mathrm{CO}$ conversion of $\mathrm{ZnCr} / \mathrm{low}-\mathrm{Si} \mathrm{AlPO}-18$ and $\mathrm{ZnCr} / \mathrm{SAPO}-34$ bifunctional catalysts increases with the decrease of GHSV, while the selectivity of $\mathrm{C} 2-\mathrm{C} 4$ olefins is gradually dropped. As shown in Fig. 3b, we can see that by increasing pressure from 4 to $10 \mathrm{MPa}\left(3600 \mathrm{~h}^{-1}, 390^{\circ} \mathrm{C}, \mathrm{CO} / \mathrm{H}_{2}=1\right)$, the $\mathrm{CO}$ conversion of $\mathrm{ZnCr} / \mathrm{low}-\mathrm{Si}$ AlPO- 18 catalyst is obviously improved from 25.2 to $49.3 \%$ while the selectivity to $\mathrm{C} 2-\mathrm{C} 4$ olefins is only slightly decreased from 45.0 to $43.3 \%$. In addition, $\mathrm{H}_{2} / \mathrm{CO}$ mole ratio is another effect on this conversion. As shown in Supplementary Table 3, with an increase in $\mathrm{H}_{2} / \mathrm{CO}$ mole ratio, the $\mathrm{CO}$ conversion rises while the $\mathrm{H}_{2}$ conversion drops obviously. As high $\mathrm{H}_{2}$ concentration may facilitate the olefins hydrogenation and reverse water-gas shift reaction, our results show gradual decrease in the selectivity to $\mathrm{C} 2-\mathrm{C} 4$ olefins

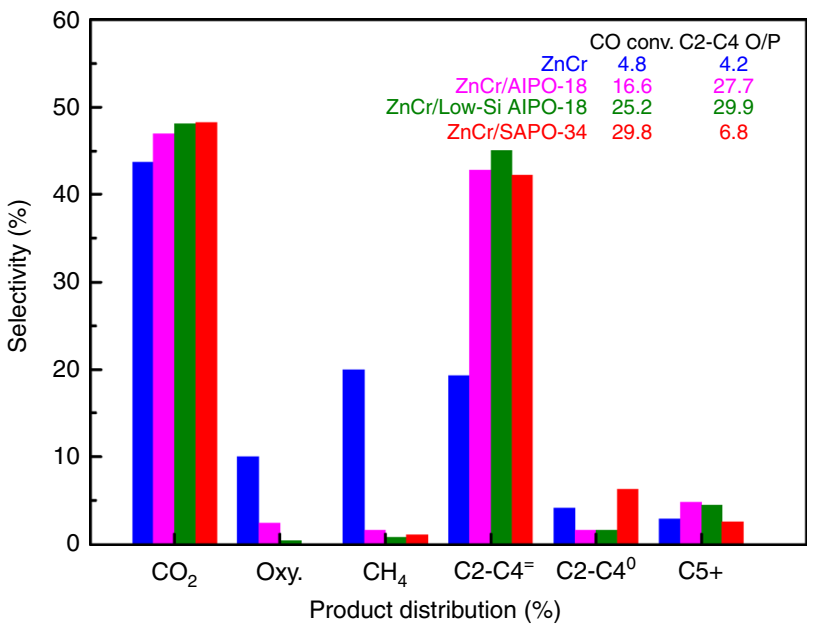

Fig. 2 Catalytic performance of bifunctional catalyst. Reaction conditions: $390^{\circ} \mathrm{C}, 4.0 \mathrm{MPa}, 1200 \mathrm{~h}^{-1}, \mathrm{H}_{2} / \mathrm{CO}=1, \mathrm{OX} / \mathrm{ZEO}=1$ (Oxy.: oxygenates including ethanol and methyl ether; C2-C4 O/P: C2-C4 olefin/paraffin ratio; $\mathrm{C} 2-\mathrm{C} 4=$ : $\mathrm{C} 2-\mathrm{C} 4$ olefins; $\mathrm{C} 2-\mathrm{C} 40$ : $\mathrm{C} 2-\mathrm{C} 4$ paraffins; $\mathrm{C} 5+$ : hydrocarbon products with more than five carbon)

Table 1 Chemical compositions, BET surface areas and pore volumes of the calcined zeolites

\begin{tabular}{|c|c|c|c|c|c|}
\hline Sample & $\begin{array}{l}\text { Si/Al mole } \\
\text { ratio }^{a}\end{array}$ & BET surface areab $\left(m^{2} g^{-1}\right)$ & Micropore area ${ }^{b}\left(m^{2} g^{-1}\right)$ & Total pore volume ${ }^{b}\left(\mathrm{~cm}^{3} \mathrm{~g}^{-1}\right)$ & Micropore volume ${ }^{b}\left(\mathrm{~cm}^{3} \mathrm{~g}^{-1}\right)$ \\
\hline AIPO-18 & 0 & 592 & 501 & 0.64 & 0.23 \\
\hline low-Si AIPO-18 & 0.013 & 467 & 384 & 0.60 & 0.18 \\
\hline SAPO-34 & 0.13 & 493 & 490 & 0.27 & 0.23 \\
\hline
\end{tabular}



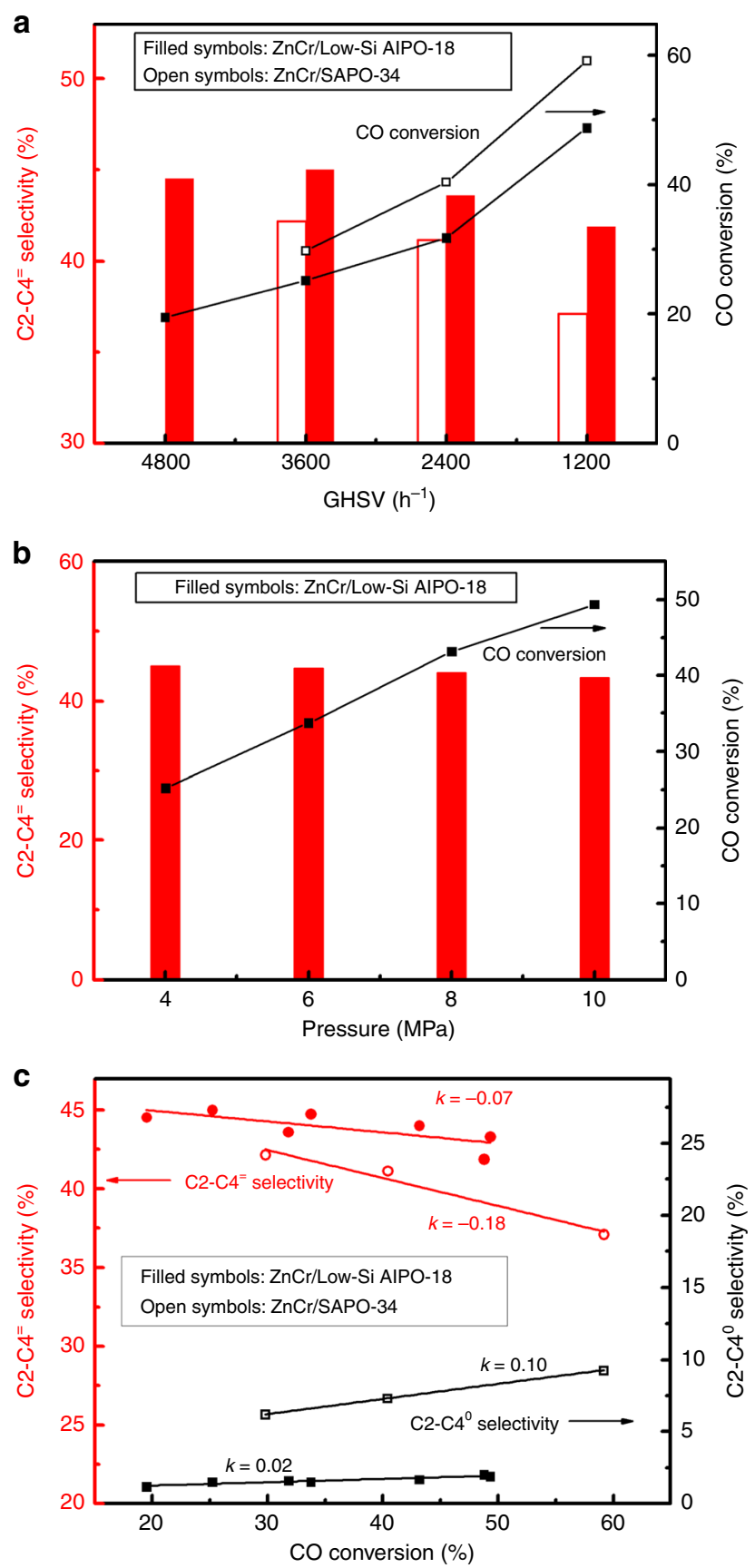

Fig. 3 Effect of reaction conditions on catalytic performance. a Effect of GHSV on CO hydrogenation over $\mathrm{ZnCr} / \mathrm{low}-\mathrm{Si} \mathrm{AlPO}-18$ and $\mathrm{ZnCr} / \mathrm{SAPO}-$ 34 bifunctional catalysts; Other conditions: $390^{\circ} \mathrm{C}, 4.0 \mathrm{MPa}, \mathrm{H}_{2} / \mathrm{CO}=1$. b Effect of pressure on $\mathrm{CO}$ hydrogenation over $\mathrm{ZnCr} / \mathrm{low}-\mathrm{Si}$ AlPO-18 bifunctional catalysts; Other conditions: $390^{\circ} \mathrm{C}, 3600 \mathrm{~h}^{-1}, \mathrm{H}_{2} / \mathrm{CO}=1$. c Relation between $\mathrm{CO}$ conversion and $\mathrm{C} 2-\mathrm{C} 4$ product selectivity ( $\mathrm{ZnCr} / \mathrm{low}-\mathrm{Si}$ AIPO-18: filled symbols, $\mathrm{ZnCr} / \mathrm{SAPO}-34$ : open symbols)

and $\mathrm{CO}_{2}$ as $\mathrm{H}_{2} / \mathrm{CO}$ increases despite of the increase of carbon utilization (selectivity to hydrocarbons).

From Fig. 3c, it was observed that increasing the $\mathrm{CO}$ conversion would inevitably lead to the decrease in $\mathrm{C} 2-\mathrm{C} 4$ olefins selectivity, as depicted by linear relations, but the slope of those trends varies with zeolite component. Obviously, $\mathrm{ZnCr} /$ SAPO-34 shows a much sharper declining slope in C2-C4 olefins selectivity than $\mathrm{ZnCr} /$ low-Si AlPO-18 when increasing $\mathrm{CO}$ conversion. By optimizing reaction conditions, we can achieve a very high CO conversion of more than $50 \%$ for the $\mathrm{ZnCr} / \mathrm{SAPO}-$ 34. However, it is difficult to keep the $\mathrm{C} 2-\mathrm{C} 4$ olefin selectivity higher than $80 \%\left(\mathrm{CO}_{2}\right.$ free $)$ at the same time, which has also been proved in Bao's work ${ }^{19}$. On the contrary, using $\mathrm{ZnCr} / \mathrm{low}-\mathrm{Si}$ AlPO-18 catalyst, it is possible to achieve both high $\mathrm{C} 2-\mathrm{C} 4$ olefin selectivity and high CO conversion simultaneously, offering potential for industrial application.

Structure and performance relationship. We are now at the position to figure out why the performance of $\mathrm{ZnCr} / \mathrm{AlPO}-18$ and $\mathrm{ZnCr} /$ low-Si AlPO-18 can be obviously improved compared with $\mathrm{ZnCr} / \mathrm{SAPO}-34$. Because the same $\mathrm{ZnCrO}_{\mathrm{x}}$ was used, the change in catalytic behaviors is mainly caused by the zeolite component. After excluding the influence of particle size on hydrocarbon distribution, it is obvious that both SAPO-34 and low-Si AlPO-18 zeolites mainly differ in $\mathrm{Si} / \mathrm{Al}$ ratio and framework structures as characterized above. It is therefore difficult to make a direct comparison between the two zeolites. We here construct a bridge between SAPO-34 and low-Si AlPO-18 by synthesizing the low-Si AlPO-34 zeolite, which shows similar Si/Al ratio of 0.013 with low-Si AlPO-18 (Supplementary Table 4). By combining with the same $\mathrm{ZnCrO}_{\mathrm{x}}$, we measured its activity in syngas conversion under the same reaction conditions. The $\mathrm{ZnCr} / \mathrm{low}-\mathrm{Si}$ AlPO-34 bifunctional catalyst shows a C2-C4 olefin selectivity of $84.3 \%$ $\left(\mathrm{CO}_{2}\right.$ free) with a $\mathrm{CO}$ conversion of $24.9 \%$ (Supplementary Table 1). The obtained olefin/paraffin ratio is 10.5 , which is slightly higher than that of $\mathrm{ZnCr} / \mathrm{SAPO}-34$ (6.8) while much lower than that of $\mathrm{ZnCr} / \mathrm{low}-\mathrm{Si}$ AlPO-18 (29.9).

Because SAPO-34 and low-Si AlPO-34 have the same CHA framework topology structure, the differences in catalytic performance are largely caused by zeolite acidity. FTIR spectra were applied to characterize the acidity of zeolite, using $\mathrm{CD}_{3} \mathrm{CN}$ or $\mathrm{CO}$ as probe molecules 27,28 . As shown in Fig. $4 \mathrm{a}$, three peaks at 3678,3626 , and $3601 \mathrm{~cm}^{-1}$ are observed in the FTIR spectra of calcined zeolites after vacuum dehydration at $400{ }^{\circ} \mathrm{C}$, corresponding to different types of hydroxyl vibrations. The peak at $3678 \mathrm{~cm}^{-1}$ is assigned to $\mathrm{Al}-\mathrm{OH}$ or $\mathrm{P}-\mathrm{OH}$, the other two peaks are assigned to the $\operatorname{HF}\left(3626 \mathrm{~cm}^{-1}\right)$ and $\operatorname{LF}\left(3601 \mathrm{~cm}^{-1}\right)$ Si-OH-Al bridging hydroxyl groups ${ }^{28,29}$, known as Brønsted acid sites in SAPO zeolites. Compared with SAPO-34, the total areas of two $\mathrm{Si}-\mathrm{OH}-\mathrm{Al}$ peaks for low-Si AlPO-34 zeolites are obviously smaller, indicating that the total concentration of Brønsted acid sites (acid density) in low-Si AlPO-34 is much lower than SAPO-34. Similar results are also obtained using in situ $\mathrm{CD}_{3} \mathrm{CN}$ FTIR (Brønsted acid sites, $2293 \mathrm{~cm}^{-1}$, Fig. 4b). Interestingly, previous work ${ }^{30}$ has shown that the isolation of Brønsted acid sites is beneficial to maximize olefin selectivity by preventing secondary reactions in MTO process. In this aspect, the decrease of acid density also helps to promote the acid site isolation. Considering the catalytic difference in SAPO-34 and low-Si AlPO-34 zeolites, we demonstrated that reducing the acid density of zeolites and/or promoting the isolation of acid sites is beneficial to slightly increase the olefin/paraffin ratio, consistent with previous work $19,20,30$.

Another key parameter of zeolite acidity is the acid strength, which may also affect on catalytic performance. As the $\mathrm{Si} / \mathrm{Al}$ ratio of low-Si AlPO-18 and low-Si AlPO-34 was similar, no obvious difference in acid amount is observed in the FTIR spectra $3630-3590 \mathrm{~cm}^{-1}$ region (Fig. 4a) ${ }^{28}$. However, $\mathrm{CD}_{3} \mathrm{CN}-\mathrm{FTIR}$ spectra (Fig. 4b) show that there exists slight shift in peak positions ascribed to Brønsted acid sites for low-Si AlPO-34 $\left(2293 \mathrm{~cm}^{-1}\right)$ and low-Si AlPO-18 $\left(2287 \mathrm{~cm}^{-1}\right)$. Fitting results show that there are two kinds of Brønsted acid sites: $\mathrm{Si}-\mathrm{OH}-\mathrm{Al}$ bridging hydroxyl groups $\left(2293 \mathrm{~cm}^{-1}\right)$, and $\mathrm{P}-\mathrm{OH}\left(2282 \mathrm{~cm}^{-1}\right)$, respectively, where the acid strength of $\mathrm{P}-\mathrm{OH}$ is weaker than that 
a

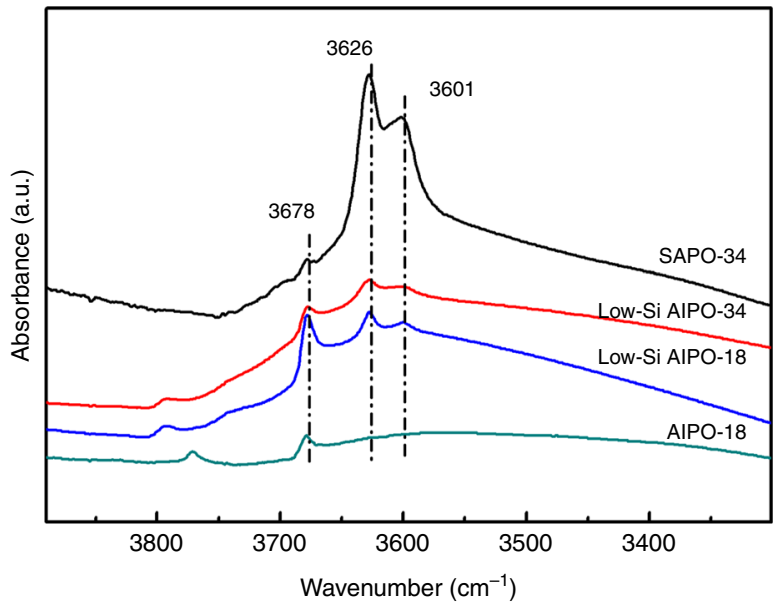

b

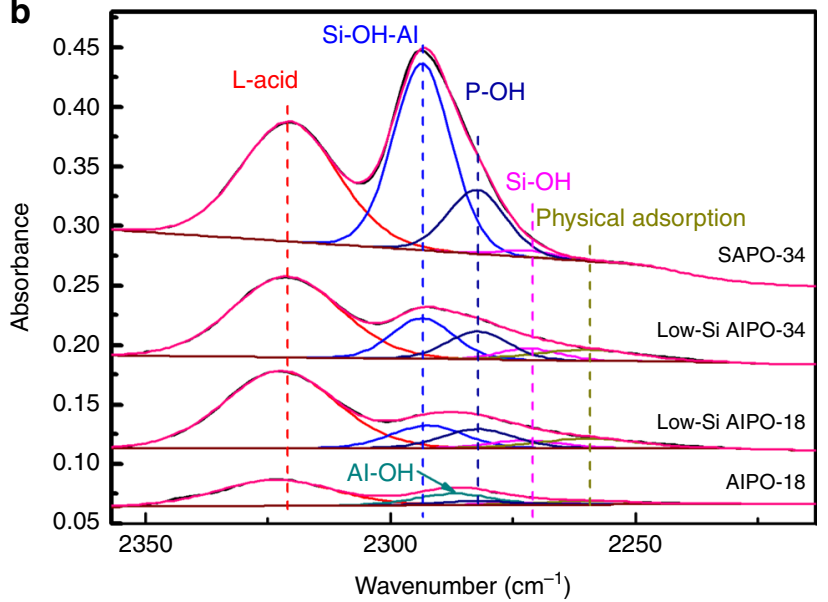

Fig. 4 FTIR spectra. a FTIR spectra of calcined low-Si AIPO-18, low-Si AIPO34 , and SAPO-34 zeolites after vacuum dehydration at $400^{\circ} \mathrm{C}$. b Fitted FTIR spectra of $\mathrm{CD}_{3} \mathrm{CN}$ adsorption over calcined AIPO-18, low-Si AIPO-18, low-Si AIPO-34, and SAPO-34 zeolites at room temperature

of Si-OH-Al hydroxyl group. In addition, according to the quantified results (Supplementary Table 3), the acid density in low-Si AlPO-18 was similar with low-Si AlPO-34 but the acid strength of low-Si AlPO-34 is stronger than the low-Si AlPO-18. No peaks assigned to $\mathrm{Si}-\mathrm{OH}-\mathrm{Al}$ bridging hydroxyl groups is observed from FTIR spectrum of the AlPO-18 zeolites(Fig. 4a), but there also exists a broad peak at $2287 \mathrm{~cm}^{-1}$ ascribed to Brønsted acid sites composed of $\mathrm{P}-\mathrm{OH}$ or $\mathrm{Al}-\mathrm{OH}$.

In situ CO-FTIR was also employed to further determine the acidity difference between low-Si AlPO-34 and low-Si AlPO-18 zeolites (Fig. 5). After $\mathrm{CO}$ adsorption, the peak assigned to HF $\mathrm{Si}-\mathrm{OH}-\mathrm{Al}$ hydroxyl group in low-Si AlPO-34 shifts from $3635^{1}$ to $3358 \mathrm{~cm}^{-1}$ (difference $227 \mathrm{~cm}^{-1}$ ). The FTIR spectrum of low-Si AlPO-18 zeolite at low $\mathrm{CO}$ adsorption pressure $(5.0 \mathrm{E}-9 \mathrm{mbar})$ is similar to that of low-Si AlPO-34. But under higher $\mathrm{CO}$ adsorption pressure, an additional $\mathrm{OH}$ peak shifts from $3675 \mathrm{~cm}^{-1}$ to $3490 \mathrm{~cm}^{-1}$ (difference $185 \mathrm{~cm}^{-1}$ ), assigned to $\mathrm{P}-\mathrm{OH}$ group 28 and the same shifts are also observed for AlPO-18 zeolite. The smaller shift wavenumber indicates that the acid strength of $\mathrm{P}-\mathrm{OH}$ is weaker than that of $\mathrm{Si}-\mathrm{OH}-\mathrm{Al}$ hydroxyl group. In addition, the peak intensity of the $\mathrm{P}-\mathrm{OH}$ is close to the $\mathrm{Si}-\mathrm{OH}-\mathrm{Al}$ hydroxyl group, and thus demonstrates that $\mathrm{P}-\mathrm{OH}$ is one of the main sources of Brønsted acid sites in AlPO-18 and low-Si AlPO-18 zeolites. These results show that, despite of difference in pore structures, the weaker acid strength should be one of main reasons for the obvious increase of olefin/paraffin ratio over bifunctional catalyst containing AlPO-18 or low-Si AlPO-18 zeolite.

In the bifunctional catalysts for the direct conversion of syngas to light olefins, methanol, and/or ketene were previously suggested as the key intermediate produced on oxides and transformed in zeolites to olefins ${ }^{19,20}$. We have theoretically proved that the ketene to olefins conversion proceeds via the hydrocarbon pool mechanism, similar to the MTO conversion in zeolites where CO or $\mathrm{H}_{2} \mathrm{O}$ were, respectively, formed in both cycles ${ }^{31}$. Therefore, the selectivity of olefins mainly correlates with the distribution of cracking precursors, highly affected by the structure of zeolites (e.g., acidity, topology) and reaction conditions ${ }^{2,32}$. It was found that the hydride-transfer reaction between two olefins highly contributes to the formation of alkanes in Brønsted acid zeolites, and which should be suppressed to achieve high olefin/paraffin ratio. Periodic density functional theory (DFT) calculations were performed to understand the effect of zeolite framework on the activity of the hydride transfer, and finally on the distribution of paraffins. The hydride transfer between methoxide and 1-butene was used as the model reaction. The enthalpy barrier at $0 \mathrm{~K}$ was calculated to be $105 \mathrm{~kJ} \mathrm{~mol}^{-1}$ in $\mathrm{H}-\mathrm{SAPO}-34$, much lower than the results in H-SAPO-18 in which several different acidic sites were considered (126 157 kJ mol${ }^{-1}$, see Fig. 6). These results indicated that H-SAPO-18 is less reactive than H-SAPO-34 for the hydride transfer, leading to a relatively higher olefin/paraffin ratio in AEIstructured zeolites as observed in experiments. Regarding the intermediate species, we speculated that methanol is likely to play a greater role than ketene, since relatively larger amounts of oxygenates (methanol or DME) are produced on pure $\mathrm{ZnCrO}_{\mathrm{x}}$ and ketene is less reactive than methanol for the chain propagation in the hydrocarbon pool mechanism ${ }^{31,33}$.

Stability of bifunctional catalyst. Finally, we can rationalize the excellent catalytic performance of $\mathrm{ZnCr} / \mathrm{low}-\mathrm{Si}$ AlPO-18 catalyst from the points of acid strength, acid density, and framework structures of zeolite component. In addition, the catalyst stability is also a key indicator in industrial applications, and thus we tested the stability of $\mathrm{ZnCr} / \mathrm{low}-\mathrm{Si} \mathrm{AlPO}-18$ catalyst for $500 \mathrm{~h}$ under reaction conditions of $390^{\circ} \mathrm{C}, 4.0 \mathrm{Mpa}, 1200 \mathrm{~h}^{-1}$, and $\mathrm{H}_{2} / \mathrm{CO}=1$. As shown in Fig. 7, CO conversion keeps stable at around $45 \%$, meanwhile, $\mathrm{C} 2-\mathrm{C} 4=$ selectivity maintains at the value of $43 \%$ and the olefin/paraffin ratio is always $\sim 20$. The TGA curves (Supplementary Fig. 2) of used catalysts shows that there are 1.5 and 15\% weight loss in $\mathrm{ZnCrO}_{\mathrm{x}}$ and low-Si AlPO-18 zeolite, respectively, which contain volatile species and occluded organic deposits. After removal of volatile components in $\mathrm{N}_{2}$ flow, $3.5 \%$ of carbon deposit amount is obtained by measuring the amount of $\mathrm{CO}_{2}$ formed from the combustion of the used bifunctional catalyst. Therefore, $\mathrm{ZnCr} /$ low-Si AlPO-18 is a highly potential candidate of bifunctional catalyst for the direct synthesis of light olefins from syngas with high olefin/paraffin ratio and superior stability.

\section{Discussion}

In summary, a series of zeolites with AEI framework were synthesized and were employed to catalyze the direct conversion of syngas to light olefins combining with $\mathrm{ZnCrO}_{\mathrm{x}}$. Compared with the bifunctional catalysts containing zeolites with CHA framework, $\mathrm{ZnCr} /$ low-Si AlPO-18 catalyst shows an excellent catalytic performance with high $\mathrm{CO}$ conversion and light olefins selectivity in direct conversion of syngas with low $\mathrm{H}_{2} / \mathrm{CO}$ ratio (1:1). The selectivity to $\mathrm{C} 2-\mathrm{C} 4$ olefins reaches up to $45.0 \%\left(86.7 \%, \mathrm{CO}_{2}\right.$ free) with an olefin/paraffin ratio of 29.9 at a CO conversion of $25.2 \%$. By optimizing the reaction conditions, even higher $\mathrm{CO}$ conversion of $49.3 \%$ with a C2-C4 olefins selectivity of $43.3 \%(83.4 \%$, $\mathrm{CO}_{2}$ free) and olefin/paraffin ratio of 22.5 is achieved. The catalyst is found to exhibit high stability; no obvious decline in 

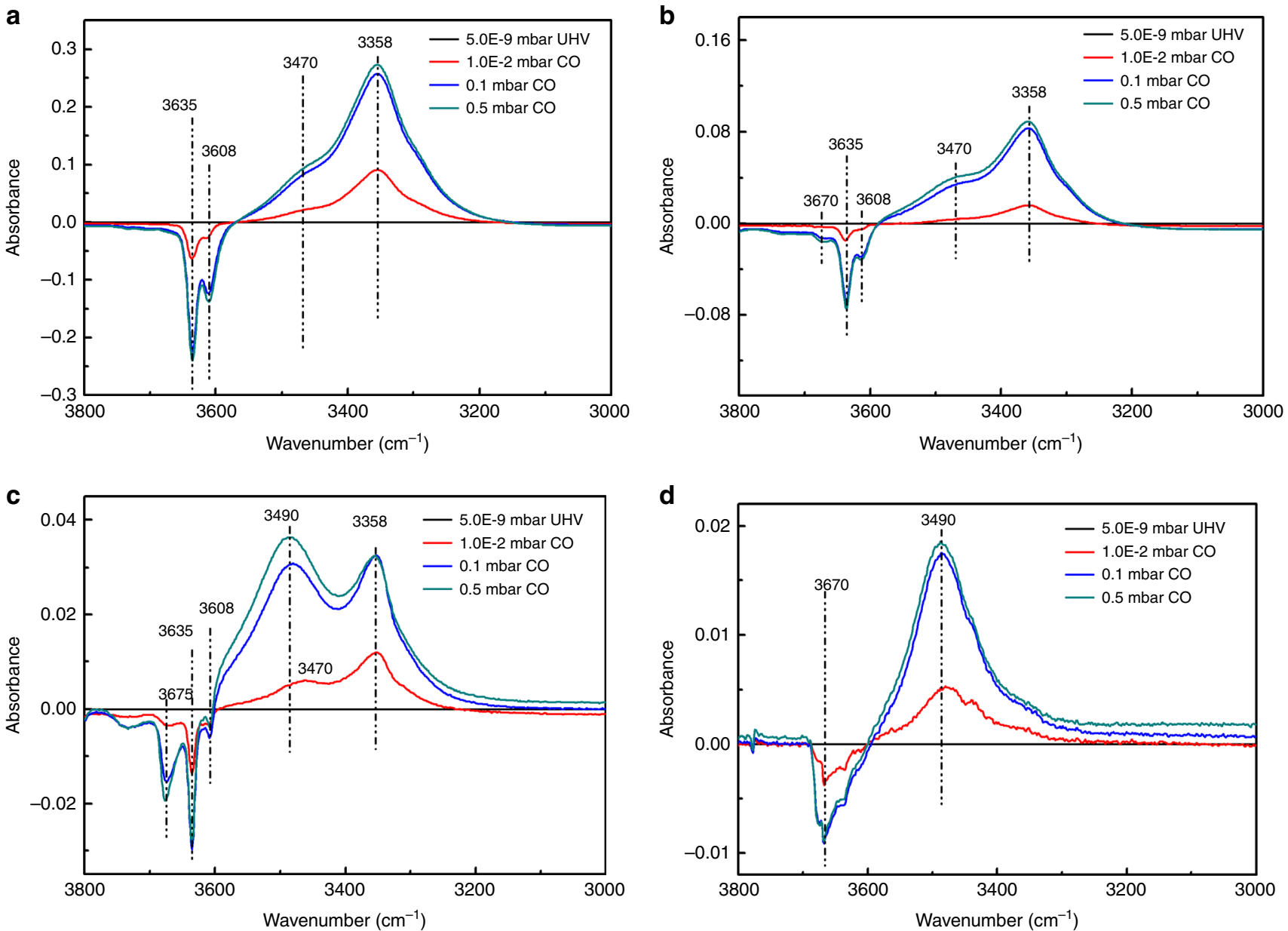

Fig. 5 In situ FTIR spectra of CO adsorption. a SAPO-34; b low-Si AIPO-34; c low-Si AIPO-18; and d AIPO-18 (UHV: ultra-high vacuum)
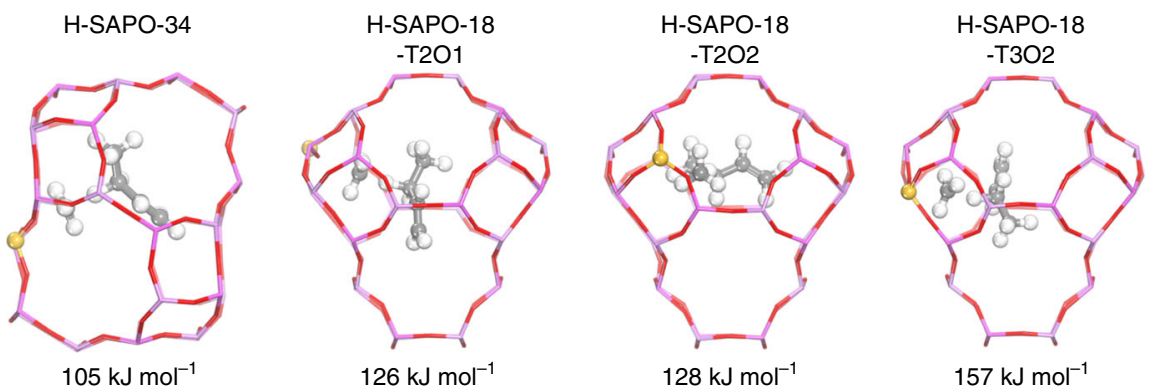

Fig. 6 Hydride transfer barrier. Calculated hydride transfer barrier between methoxide and 1-butene in H-SAPO-34 and H-SAPO-18 zeolites

performance was observed after the time-on-stream of $500 \mathrm{~h}$. FTIR characterization approaches and DFT calculations demonstrated that low-Si AlPO-18 zeolite has low acid density and strength and is less reactive for the hydride transfer compared with low-Si AlPO-34 and SAPO-34 zeolites, leading to a higher selectivity to light olefins. Our results pave the way for developing improved catalysts for the industrialization of direct light olefins synthesis from syngas.

\section{Methods}

Synthesis of the $\mathbf{Z n C r O}_{\mathbf{x}}$. $\mathrm{ZnCrO}_{\mathrm{x}}$ was prepared via a co-precipitation method. Analytical grade chemical reagents were used in the experiment without any further purification. Typically, appropriate amount of zinc nitrate $\left(\mathrm{Zn}\left(\mathrm{NO}_{3}\right)_{2} \cdot 6 \mathrm{H}_{2} \mathrm{O}\right.$; bought from Sinopharm Chemical Reagent Co.) and chromium nitrate $(\mathrm{Cr}$ $\left(\mathrm{NO}_{3}\right)_{4} \cdot 9 \mathrm{H}_{2} \mathrm{O}$; Sinopharm Co.) were dissolved in deionized water to form a mixed salt solution (the total concentration of metal ion is $1.0 \mathrm{~mol} \mathrm{~L}^{-1}$ ). Meanwhile, ammonium carbonate anhydrous $\left(\left(\mathrm{NH}_{4}\right)_{2} \mathrm{CO}_{3}\right.$; Sinopharm Co. $)$ was dissolved in deionized water, resulting in a basic solution $\left(1.0 \mathrm{~mol} \mathrm{~L}^{-1}\right)$ as precipitant. And then, these two solutions were simultaneously added, dropwise, into a beaker containing $20 \mathrm{~mL}$ deionized water under continuous stirring at $70^{\circ} \mathrm{C}$. The $\mathrm{pH}$ value of the aqueous solution was kept at 7.0-8.0 by adjusting the addition rate of basic solution. After stirring for $2 \mathrm{~h}$ at $70^{\circ} \mathrm{C}$, the precipitate was obtained via filtration and washing with deionized water. After dried at $80^{\circ} \mathrm{C}$ for $12 \mathrm{~h}$, the samples were then calcined in a muffle furnace at $500{ }^{\circ} \mathrm{C}$ for $1 \mathrm{~h}$ with a ramping rate of $2{ }^{\circ} \mathrm{C} \mathrm{min}{ }^{-1}$ under static air. The obtained binary oxides were denoted as $\mathrm{ZnCr}$.

Synthesis of the zeolites. AlPO- 18 was synthesized as the following: $24.5 \mathrm{~g}$ aluminum isopropoxide $\left(\mathrm{Al}_{2} \mathrm{O}_{3}, 74.6 \%\right)$ was added into the mixture prepared by combining $15.0 \mathrm{~g}$ of $\mathrm{H}_{3} \mathrm{PO}_{4}(85 \%)$ and $36.3 \mathrm{~g}$ of water, stirred until homogeneous. Then, $49 \mathrm{~g}$ of TEAOH (40\%) was added and the mixture was further stirred until homogeneous. The composition of the final reaction mixture in molar oxide ratios was $0.9 \mathrm{Al}_{2} \mathrm{O}_{3}: \mathrm{P}_{2} \mathrm{O}_{5}:(\text { TEA) })_{2} \mathrm{O}: 60 \mathrm{H}_{2} \mathrm{O}: 5.4 \mathrm{i}-\mathrm{C}_{3} \mathrm{H}_{7} \mathrm{OH}$. The reaction mixture was sealed in a stainless steel pressure vessel lined with an inert plastic material (polytetrafluoroethylene) and heated in an oven at $170^{\circ} \mathrm{C}$ at autogenous pressure 


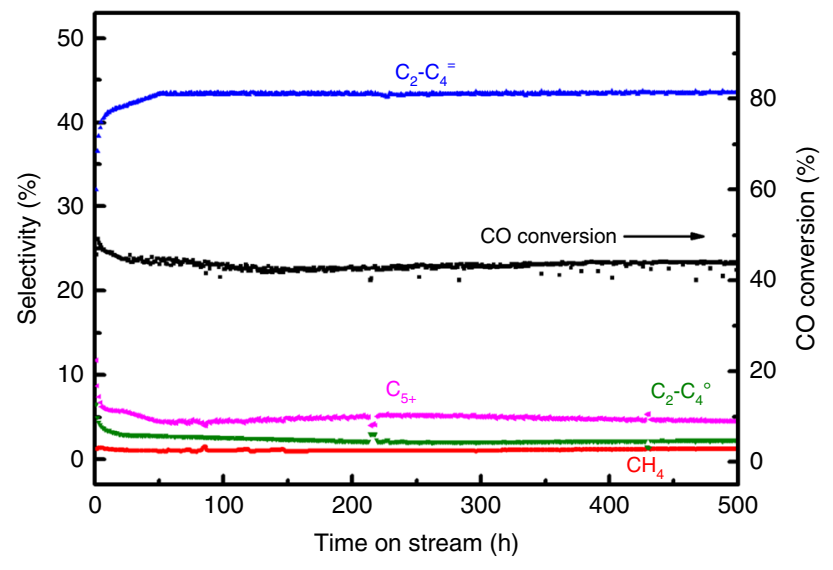

Fig. 7 Stability of catalyst. Time-on-stream of CO conversion and selectivity for $\mathrm{ZnCr} /$ low-Si AlPO-18 bifunctional catalyst. Reaction conditions: $390^{\circ} \mathrm{C}$, 4.0 $\mathrm{MPa}, 1200 \mathrm{~h}^{-1}, \mathrm{H}_{2} / \mathrm{CO}=1$, and oxide/zeolite mass ratio $=1$. $\left(\mathrm{C} 2-\mathrm{C}_{4}=\right.$ : C2-C4 olefins; $\mathrm{C2}-\mathrm{C} 4 \mathrm{O}$ : $\mathrm{C2}-\mathrm{C} 4$ paraffins; $\mathrm{C} 5+$ : hydrocarbon products with more than five carbon)

for $48 \mathrm{~h}$. The solid reaction product was recovered by filtration, washed with water, and dried at $100^{\circ} \mathrm{C}$ over night, followed by calcination at $550^{\circ} \mathrm{C}$ for $4 \mathrm{~h}$ with a heating rate of $2{ }^{\circ} \mathrm{C} \mathrm{min}-1$ to remove the occluded organic species.

Low-Si AlPO-18 was synthesized as the following: $27.4 \mathrm{~g}$ boehmite $\left(\mathrm{Al}_{2} \mathrm{O}_{3}\right.$, $74.6 \%$ ) was added into the mixture prepared by combining $46.1 \mathrm{~g}$ of $\mathrm{H}_{3} \mathrm{PO}_{4}(85 \%)$ and $119.2 \mathrm{~g}$ of water, stirred until homogeneous. Then, $\mathrm{HCl}$ solution $(37 \%)$ and TEAOH $(25 \%)$ were added and the mixture was further stirred until homogeneous. The composition of the final reaction mixture in molar oxide ratios was $0.33 \mathrm{HCl}: 0.67(\mathrm{TEA})_{2} \mathrm{O}: \mathrm{Al}_{2} \mathrm{O}_{3}: \mathrm{P}_{2} \mathrm{O}_{5}: 40 \mathrm{H}_{2} \mathrm{O}$. The reaction mixture was sealed in a stainless steel pressure vessel lined with an inert plastic material (polytetrafluoroethylene) and heated in an oven at $170^{\circ} \mathrm{C}$ at autogenous pressure for $72 \mathrm{~h}$. The solid reaction product was recovered by filtration, washed with water, and dried at $100^{\circ} \mathrm{C}$ over night, followed by calcination at $550^{\circ} \mathrm{C}$ for $5 \mathrm{~h}$ with a heating rate of $2{ }^{\circ} \mathrm{C} \mathrm{min}^{-1}$ to remove the occluded organic species.

AlPO-18- $\mathrm{L}$ was synthesized as the following: $27.2 \mathrm{~g}$ aluminum isopropoxide $\left(\mathrm{Al}_{2} \mathrm{O}_{3}\right.$, $74.6 \%$ ) was added into the mixture prepared by combining $15.0 \mathrm{~g}$ of $\mathrm{H}_{3} \mathrm{PO}_{4}(85 \%)$ and $36.3 \mathrm{~g}$ of water, stirred until homogeneous. Then, $49 \mathrm{~g}$ of TEAOH (40\%) was added and the mixture was further stirred until homogeneous. The composition of the final reaction mixture in molar oxide ratios was $1.0 \mathrm{Al}_{2} \mathrm{O}_{3}: \mathrm{P}_{2} \mathrm{O}_{5}:(\mathrm{TEA})_{2} \mathrm{O}: 60$ $\mathrm{H}_{2} \mathrm{O}: 5.4 \mathrm{i}-\mathrm{C}_{3} \mathrm{H}_{7} \mathrm{OH}$. The reaction mixture was sealed in a stainless steel pressure vessel lined with an inert plastic material (polytetrafluoroethylene) and heated in an oven at $200^{\circ} \mathrm{C}$ at autogenous pressure for $96 \mathrm{~h}$. The solid reaction product was recovered by filtration, washed with water, and dried at $100^{\circ} \mathrm{C}$ over night, followed by calcination at $550^{\circ} \mathrm{C}$ for $4 \mathrm{~h}$ with a heating rate of $2{ }^{\circ} \mathrm{C} \mathrm{min}^{-1}$ to remove the occluded organic species

Low-Si AlPO-34 was synthesized as the following: $27.4 \mathrm{~g}$ boehmite $\left(\mathrm{Al}_{2} \mathrm{O}_{3}\right.$, $74.6 \%$ ) was added into the mixture prepared by combining $46.1 \mathrm{~g}$ of $\mathrm{H}_{3} \mathrm{PO}_{4}(85 \%)$ and $119.2 \mathrm{~g}$ of water, stirred until homogeneous. Then, morpholine and HF were added in succession with the composition of the final reaction mixture in molar oxide ratios being $0.25 \mathrm{HF}: 6.0 \mathrm{Mor}$ ::1.0 $\mathrm{Al}_{2} \mathrm{O}_{3}: 1.0 \mathrm{P}_{2} \mathrm{O}_{5}: 100 \mathrm{H}_{2} \mathrm{O}$. The resultant mixtures were stirred for $1 \mathrm{~h}$ at room temperature and then was sealed in a stainless steel pressure vessel lined with an inert plastic material (polytetrafluoroethylene) and heated in an oven at $200^{\circ} \mathrm{C}$ at autogenous pressure for $72 \mathrm{~h}$. The solid reaction product was recovered by filtration, washed with water, and dried at $100^{\circ} \mathrm{C}$ over night, followed by calcination at $550^{\circ} \mathrm{C}$ for $5 \mathrm{~h}$ with a heating rate of $2{ }^{\circ} \mathrm{C} \mathrm{min}^{-1}$ to remove the occluded organic species.

SAPO- 34 was synthesized as the following: $27.4 \mathrm{~g}$ boehmite $\left(\mathrm{Al}_{2} \mathrm{O}_{3}, 74.6 \%\right)$ was added into the mixture prepared by combining $46.1 \mathrm{~g}$ of $\mathrm{H}_{3} \mathrm{PO}_{4}(85 \%)$ and $119.2 \mathrm{~g}$ of water, stirred until homogeneous. Then, triethylamine (TEA) was added into the mixture with the composition of the final reaction mixture in molar oxide ratios being $0.15 \mathrm{SiO}_{2}: 1.0 \mathrm{Al}_{2} \mathrm{O}_{3}: 0.8 \mathrm{P}_{2} \mathrm{O}_{5}: 3.0 \mathrm{TEA}: 50 \mathrm{H}_{2} \mathrm{O}$. The resultant mixtures were stirred for $1 \mathrm{~h}$ at room temperature and then was sealed in a stainless steel pressure vessel lined with an inert plastic material (polytetrafluoroethylene) and heated in an oven at $200^{\circ} \mathrm{C}$ at autogenous pressure for $24 \mathrm{~h}$. The solid reaction product was recovered by filtration, washed with water, and dried at $100^{\circ} \mathrm{C}$ over night, followed by calcination at $550^{\circ} \mathrm{C}$ for $5 \mathrm{~h}$ with a heating rate of $2^{\circ} \mathrm{C} \mathrm{min}^{-1}$ to remove the occluded organic species.

Preparation of bifunctional catalysts. For the preparation of the bifunctional catalysts, the $\mathrm{ZnCrO}_{\mathrm{x}}$ and the zeolites were pressed, crushed, and sieved to granules in the range of $20-40$ mesh, respectively. Then, the granules of the two samples were mixed together by shaking in a vessel.
Catalyst characterization. XRD patterns were obtained using Bruker D8 Advance diffractometer, with an accelerated voltage of $40 \mathrm{kV}$ and detector current of $200 \mathrm{~mA}$. Cu- $\mathrm{K}_{\alpha}$ radiation $(\lambda=51.540589 \AA)$ was used for a continuous scanning with the step-size of $0.02^{\circ}$ over a $2 \theta$ range of $5-60^{\circ}$. The crystal size of oxide particles was calculated with the width of diffraction patterns, referring to the full width of half maximum (FWHM) of crystalline facets at (311) for $\mathrm{ZnCr}_{2} \mathrm{O}_{4}$ using Debye-Scherrer formula.

$\mathrm{N}_{2}$ Adsorption and desorption isotherms were collected on Micromeritics TriStar 3000 at $75 \mathrm{~K}$. Prior to the measurements, the sample was degassed at $350{ }^{\circ} \mathrm{C}$ until a stable vacuum of about $0.67 \mathrm{~Pa}$ was reached.

The chemical compositions of the calcined samples were determined by inductively coupled plasma atomic emission spectroscopy.

FE-SEM (Field Emission Scanning Electron Microscopy) analysis was performed on a Hitachi $\$ 4800$ electron microscope with an accelerating voltage of $2.0 \mathrm{kV}$.

TEM images were conducted on a Tecnai 20 STWIN electron microscope operated at $200 \mathrm{kV}$. The aberration-corrected scanning transmission electron microscopy (STEM) measurements were performed on a FEI Titan Cubed Themis G2 $300 \mathrm{kV}$ with an accelerating voltage of $300 \mathrm{kV}$. The prepared samples were ultrasonically dispersed in hexane solvent during the ultrasonic treatment and then were dried over a carbon film supported on a $\mathrm{Cu}$ grid.

In situ CO-FTIR spectra were recorded using a FTIR spectrometer (Bruker Vertex 70V) equipped with a stainless steel high vacuum transmission infrared cell. The zeolite samples were pressed into spots on a tungsten mesh support. Prior to the experiment, the samples were heated to $350-400^{\circ} \mathrm{C}$ with a ramping rate of $12^{\circ} \mathrm{C} \mathrm{min}^{-1}$ in vacuum $\left(<2.0 \times 10^{-8} \mathrm{mbar}\right)$ for $2.5 \mathrm{~h}$. After cooling down to $-150^{\circ} \mathrm{C}$ by using liquid nitrogen, the background spectrum was collected. Subsequently, $1 \times 10^{-2}, 0.1$, and $0.5 \mathrm{mbar}$ of $\mathrm{CO}$ was introduced into the cell, and then the corresponding spectra were collected at $-150^{\circ} \mathrm{C}$.

In situ CD3CN-FTIR spectra were recorded using the same infrared system of CO-FTIR. After dehydrated at $350-400^{\circ} \mathrm{C}$ in vacuum $\left(<2.0 \times 10^{-8} \mathrm{mbar}\right)$ for $2.5 \mathrm{~h}$ the samples were cooled down to room temperature, and then the background spectrum was collected. Subsequently, $0.5 \mathrm{mbar}$ of $\mathrm{CD}_{3} \mathrm{CN}$ was introduced into the cell, remaining for $1 \mathrm{~h}$. Finally, $\mathrm{CD}_{3} \mathrm{CN}$ was removed and the corresponding spectra were collected in vacuum.

The amounts of occluded hydrocarbons after the $\mathrm{CO}$ hydrogenation reaction were determined by thermogravimetric analysis on a Rigaku standard type thermogravimetric analyzer. In a typical measurement, $0.1 \mathrm{~g}$ of sample was heated in an $\mathrm{Al}_{2} \mathrm{O}_{3}$ crucible with a constant heating rate of $10 \mathrm{~K} \mathrm{~min}^{-1}$ and under air purging with a flow rate of $30 \mathrm{~mL} \mathrm{~min}^{-1}$.

The amounts of carbon deposits in used zeolites were determined on a HIR944C infrared carbon and sulphur analyzer. Prior to the experiment, the sample was first pretreated at $500{ }^{\circ} \mathrm{C}$ in $\mathrm{N}_{2}\left(60 \mathrm{~mL} \mathrm{~min}^{-1}\right)$ at $0.1 \mathrm{MPa}$ with a ramping rate of $2{ }^{\circ} \mathrm{C} \mathrm{min}^{-1}$.

Catalyst evaluation. To assess the catalytic performance, experiments were carried out using a continuous stainless steel fixed-bed micro-reactor lined with a quartz tube (inner diameter, $6 \mathrm{~mm}$ ). Catalyst bed was located in the middle of the reactor. All feed gas $\left(\mathrm{H}_{2}\right.$ and syngas) were pre-purified in a trap to remove carbonyl compounds at $140^{\circ} \mathrm{C}$. Prior to the reaction, the catalyst was first reduced at $400^{\circ} \mathrm{C}$ in $\mathrm{H}_{2}\left(100 \mathrm{~mL} \mathrm{~min}^{-1}\right)$ at $0.1 \mathrm{MPa}$ with a ramping rate of $4^{\circ} \mathrm{C} \mathrm{min}^{-1}$. After pretreatment, the reactor was pressurized using $\mathrm{H}_{2} / \mathrm{CO} / \mathrm{N}_{2}(45 / 45 / 10)$ to reach the reaction pressure. Influent and effluent gases were analyzed via an online gas chromatography (Agilent-7890B). A capillary column (HP-Plot Q) connected to a flame ionization detector (FID) was used to analyze all products (hydrocarbons and oxygenates). Other gas products were analyzed using a TDX-01 packed column connected with a thermal conductivity detector (TCD). Each data for computing the reaction kinetics was acquired after $20 \mathrm{~h}$. $\mathrm{CO}$ conversion and $\mathrm{CO}_{2}$ selectivity were determined using an internal standard, and the selectivity of the carboncontaining products was calculated by an internal normalization method. The CO conversion and selectivity are defined in supplementary methods

Computational methods and modeling. All periodic DFT calculations were carried out using the Vienna Ab initio Simulation Package (VASP 5.3.5) ${ }^{34}$. The Bayesian error estimation functional with $\mathrm{vdW}$ correlation (BEEF-vdW) was employed ${ }^{35}$. The electron-ion interaction was described by the projector augmented wave (PAW) method ${ }^{36,37}$. Further details on calculation are given in the Supporting methods.

\section{Data availability}

The authors declare that the data supporting the findings of this study are available within the article and supplementary information file, or from the corresponding author upon reasonable request.

Received: 7 September 2018 Accepted: 1 March 2019 Published online: 21 March 2019 


\section{References}

1. Torres Galvis, H. M. \& de Jong, K. P. Catalysts for production of lower olefins from synthesis gas: a review. ACS Catal. 3, 2130-2149 (2013).

2. Wang, C., Wang, Y. \& Xie, Z. Insights into the reaction mechanism of methanol-to-olefins conversion in HSAPO-34 from first principles: are olefins themselves the dominating hydrocarbon pool species? J. Catal. 301, 8-19 (2013).

3. Stöcker, M. Methanol-to-hydrocarbons: catalytic materials and their behavior. Microporous Mesoporous Mater. 29, 3-48 (1999).

4. Keil, F. J. Methanol-to-hydrocarbons: process technology. Microporous Mesoporous Mater. 29, 49-66 (1999).

5. Janardanarao, M. Direct catalytic conversion of synthesis gas to lower olefins. Ind. Eng. Chem. Res. 29, 1735-1753 (1990).

6. Torres Galvis, H. M. et al. Supported iron nanoparticles as catalysts for sustainable production of lower olefins. Science 335, 835-838 (2012).

7. Zhong, L. et al. Cobalt carbide nanoprisms for direct production of lower olefins from syngas. Nature 538, 84-87 (2016).

8. Zhang, Z. et al. Promotional effects of multiwalled carbon nanotubes on iron catalysts for Fischer-Tropsch to olefins. J. Catal. 365, 71-85 (2018).

9. Wang, D., Chen, B., Duan, X., Chen, D. \& Zhou, X. Iron-based Fischer-Tropsch synthesis of lower olefins: The nature of $\chi-\mathrm{Fe}_{5} \mathrm{C}_{2}$ catalyst and why and how to introduce promoters. J. Energy Chem. 25, 911-916 (2016).

10. Zhang, Y., Ma, L., Wang, T. \& Li, X. Synthesis of Ag promoted porous $\mathrm{Fe}_{3} \mathrm{O}_{4}$ microspheres with tunable pore size as catalysts for Fischer-Tropsch production of lower olefins. Catal. Commun. 64, 32-36 (2015).

11. Cheng, Y. et al. Fischer-Tropsch synthesis to lower olefins over potassiumpromoted reduced graphene oxide supported iron catalysts. ACS Catal. 6, 389-399 (2016).

12. Lu, J. et al. Promotion effects of nitrogen doping into carbon nanotubes on supported iron Fischer-Tropsch catalysts for lower olefins. ACS Catal. 4, 613-621 (2014).

13. Torres Galvis, H. M. et al. Iron particle size effects for direct production of lower olefins from synthesis gas. J. Am. Chem. Soc. 134, 16207-16215 (2012).

14. Cheng, $K$. et al. Selective transformation of syngas into gasoline-range hydrocarbons over mesoporous H-ZSM-5-supported cobalt nanoparticles. Chem. Eur. J. 21, 1928-1937 (2015).

15. Sartipi, S., van Dijk, J. E., Gascon, J. \& Kapteijn, F. Toward bifunctional catalysts for the direct conversion of syngas to gasoline range hydrocarbons: H-ZSM-5 coated Co versus H-ZSM-5 supported Co. Appl. Catal. A Gen. 456 11-22 (2013).

16. Sartipi, S. et al. Towards liquid fuels from biosyngas: effect of zeolite structure in hierarchical-zeolite-supported cobalt catalysts. ChemSusChem 6, 1646-1650 (2013).

17. Sartipi, S. et al. Hierarchical H-ZSM-5-supported cobalt for the direct synthesis of gasoline-range hydrocarbons from syngas: Advantages, limitations, and mechanistic insight. J. Catal. 305, 179-190 (2013).

18. Zhao, B. et al. Direct transformation of syngas to aromatics over Na- $\mathrm{Zn}-\mathrm{Fe}_{5} \mathrm{C}_{2}$ and hierarchical HZSM-5 tandem catalysts. Chem 3, 323-333 (2017).

19. Jiao, F. et al. Selective conversion of syngas to light olefins. Science 351, 1065-1068 (2016).

20. Cheng, K. et al. Direct and highly selective conversion of synthesis gas to lower olefins: design of a bifunctional catalyst combining methanol synthesis and carbon-carbon coupling. Ang. Chem. Int. Ed. 55, 4725-4728 (2016).

21. Raveendra, G., Li, C., Cheng, Y., Meng, F. \& Li, Z. Direct transformation of syngas to lower olefins synthesis over hybrid $\mathrm{Zn}-\mathrm{Al}_{2} \mathrm{O}_{3} / \mathrm{SAPO}-34$ catalysts. New J. Chem. 42, 4419-4431 (2018).

22. Zhu, Y. et al. Role of manganese oxide in syngas conversion to light olefins. ACS Catal. 7, 2800-2804 (2017).

23. $\mathrm{Su}$, J. et al. Direct conversion of syngas into light olefins over zirconium-doped indium(III) oxide and SAPO-34 bifunctional catalysts: design of oxide component and construction of reaction network. ChemCatChem 10, 1536-1541 (2018).

24. Santos, V. P. et al. Metal organic framework-mediated synthesis of highly active and stable Fischer-Tropsch catalysts. Nat. Commun. 6, 6451-6458 (2015).

25. Yang, J., Pan, X., Jiao, F., Li, J. \& Bao, X. Direct conversion of syngas to aromatics. Chem. Commun. 53, 11146-11149 (2017).

26. Cheng, K. et al. Bifunctional catalysts for one-step conversion of syngas into aromatics with excellent selectivity and stability. Chem 3, 334-347 (2017).

27. Hadjiivanov, K. \& Vayssilov, G. N. Characterization of oxide surfaces and zeolites by carbon monoxide as an IR probe molecule. Adv. Catal. 47, 307-511 (2002).

28. Hadjiivanov, K. Identification and characterization of surface hydroxyl groups by infrared spectroscopy. Adv. Catal. 57, 99-318 (2014).
29. Coluccia, S. L. M. \& Martra, G. Characterisation of microporous and mesoporous materials by the adsorption of molecular probes: FTIR and UV-Vis studies. Microporous Mesoporous Mater. 30, 43-56 (1999).

30. Yarulina, I. et al. Structure-performance descriptors and the role of Lewis acidity in the methanol-to-propylene process. Nat. Chem. 10, 804-812 (2018)

31. Wang, C., Wang, Y. \& Xie, Z. Methylation of olefins with ketene in zeotypes and its implications for the direct conversion of syngas to light olefins: a periodic DFT study. Catal. Sci. Technol. 6, 6644-6649 (2016).

32. Olsbye, U. et al. Conversion of methanol to hydrocarbons: how zeolite cavity and pore size controls product selectivity. Angew. Chem. Int. Ed. 51, 5810-5831 (2012)

33. Wang, C., Brogaard, R. Y., Xie, Z. \& Studt, F. Transition-state scaling relations in zeolite catalysis: influence of framework topology and acid-site reactivity. Catal. Sci. Technol. 5, 2814-2820 (2015).

34. Kresse, G. \& Furthmuller, J. Efficient iterative schemes for $a b$ initio totalenergy calculations using a plane-wave basis set. Phys. Rev. B 54, 11169-11186 (1996).

35. Wellendorff, J. et al. Density functionals for surface science: exchangecorrelation model development with Bayesian error estimation. Phys. Rev. B 85, 235149 (2012).

36. Blochl, P. E. Projector augmented-wave method. Phys. Rev. B 50, 17953-17979 (1994).

37. Kresse, G. \& Joubert, D. From ultrasoft pseudopotentials to the projector augmented-wave method. Phys. Rev. B 59, 1758-1775 (1999).

\section{Acknowledgements}

The authors are grateful for support from the National Key Research and Development Program of China (2017YFB0702800), the China Postdoctoral Science Foundation (2017M611644), and the National Natural Science Foundation of China (21673295). Ms. Xiaohong Yuan and Dr. Yu Wang were acknowledged for their assistance during SEM and TEM experiments.

\section{Author contributions}

J.S. and H.Z. performed most of the experiments and analyzed the experimental data. Y.W. analyzed the data and co-wrote the paper. W.J., Y.Z., and H.L. performed some experiments for catalyst preparation. M.H. analyzed the results and reviewed the paper S.L., C.L., Y.Y., and L.Z. performed some experiments for catalyst characterizations. C.W performed the DFT calculation and co-wrote the paper. D.W. and W.Y. reviewed the paper. Z.X. designed the study, analyzed the experimental results, and co-wrote the paper. All authors discussed the results and reviewed the manuscript.

\section{Additional information}

Supplementary Information accompanies this paper at https://doi.org/10.1038/s41467 019-09336-1.

Competing interests: The authors declare no competing interests.

Reprints and permission information is available online at http://npg.nature.com/ reprintsandpermissions/

Journal peer review information: Nature Communications thanks Jorge Gascon, Krijn de Jong, and other anonymous reviewer(s) for their contribution to the peer review of this work. Peer reviewer reports are available.

Publisher's note: Springer Nature remains neutral with regard to jurisdictional claims in published maps and institutional affiliations.

(i) Open Access This article is licensed under a Creative Commons Attribution 4.0 International License, which permits use, sharing, adaptation, distribution and reproduction in any medium or format, as long as you give appropriate credit to the original author(s) and the source, provide a link to the Creative Commons license, and indicate if changes were made. The images or other third party material in this article are included in the article's Creative Commons license, unless indicated otherwise in a credit line to the material. If material is not included in the article's Creative Commons license and your intended use is not permitted by statutory regulation or exceeds the permitted use, you will need to obtain permission directly from the copyright holder. To view a copy of this license, visit http://creativecommons.org/ licenses/by/4.0/.

(c) The Author(s) 2019 